\title{
SAÚDE REPRODUTIVA E MULHERES INDÍGENAS DO ALTO RIO NEGRO
}

\author{
Marta Azevedo ${ }^{*}$
}

\begin{abstract}
O presente artigo descreve e analisa as concepções próprias das mulheres indígenas do Alto Rio Negro sobre saúde reprodutiva, relacionando-as a indicadores de fecundidade. As informações qualitativas apontam para um conhecimento detalhado e complexo que as mulheres indígenas dessa região possuem sobre seu corpo e os cuidados com sua saúde. Os níveis e padrões etários da fecundidade estão relacionados com a etnia das mulheres, portanto, aos sistemas tradicionais de cuidados com a saúde desses povos. A pesquisa foi desenvolvida entre 1997 e 2003, na região de Iauaretê, Terra Indígena Alto Rio Negro (AM), e teve como primeira fonte de dados o Censo Indígena Autônomo do Rio Negro - CIARN -, levado a efeito pela Federação das Organizações Indígenas do Rio Negro - FOIRN - em 1992.

PALAVRAS-CHAVE: povos indígenas, noroeste amazônico, saúde indígena, demografia e saúde, saúde da mulher.
\end{abstract}

\section{INTRODUÇÃO}

A região Alto Rio Negro é habitada atualmente por 23 povos indígenas, ${ }^{1}$ falantes de línguas das famílias Tukano, Aruak e Maku. A região faz fronteira com a Colômbia e a Venezuela, e, em 1998, teve homologadas as cinco terras indígenas demarcadas: Alto Rio Negro, Médio Rio Negro I, Médio Rio Negro II, Apapóris e Tea (Figura 1). Os povos de línguas tukano, ${ }^{2}$ todos do grupo tukano oriental, são os Barasana, Yurutí, Kubeo, Arapaso, Wanana, Desana, Pira-tapuia, Tukano, Miriti-tapuia, Bara, Karapanã e Tuyuka. Os de línguas maku são os Bará, Hupdë, Dow, Nadeb, * Doutora em Demografia. Pesquisadora do Núcleo de Estudos de População (NEPO) da UNICAMP

Cidade Universitária Zeferino Vaz. Barão Geraldo. Cep: 13083-970 - Campinas, SP - Brasil - Caixa-Postal 6166 marta@nepo.unicamp.br

${ }^{1}$ Estamos tratando aqui do que Ribeiro (1995) chama de "área cultural do rio Negro", sendo excluídos, portanto, os Yanomami, que, embora também estejam presentes na região, vivem em outra Terra Indígena, e não fazem parte dessa área cultural. Outros povos indígenas, falantes de línguas pertencentes às mesmas famílias, foram excluídos da pesquisa por habitarem comunidades localizadas nos países fronteiriços, Colômbia e Venezuela.

${ }^{2}$ As denominações Tukano (ou tukano), Maku (ou maku) grafadas em itálico significam as famílias linguísticas, ou todos os povos ou etnias pertencentes a essas famílias linguísticas.
Yuhup e Nukak (Guariba). Os de línguas aruak são os Baniwa, Baré Werekena e Tariana.

A região compreende os municípios de São Gabriel da Cachoeira e um trecho do município de Santa Isabel, ambas as cidades localizadas na margem esquerda do rio Negro. Embora com muitos anos de contato com a população não-índia, cerca de dois séculos, os habitantes dessa região são majoritariamente indígenas e permanecem identificando-se como tais. Atualmente, residem nessa região cerca de 40 mil pessoas, distribuídas em aproximadamente 700 aldeias ou comunidades nas Terras Indígenas, e ainda 14 mil pessoas que habitam o centro urbano de São Gabriel da Cachoeira (FOIRN, ISA, 2000).

A primeira fonte de dados para a presente pesquisa foi o Censo Indígena Autônomo do Rio Negro (CIARN) de 1992, que levantou informações de 380 comunidades com 60 domicílios em média (Azevedo, 2003). A partir da análise desses dados e em diálogo com as mulheres indígenas da região, decidiu-se investigar o sistema tradicional de cuidados com a saúde das mulheres e a maneira como elas percebem suas condições de saúde. 
O presente artigo descreve as concepções próprias das mulheres sobre a saúde do corpo e relaciona algumas medidas de fecundidade e parturição com as percepções que elas têm do seu corpo.

\section{SAÚDEREPRODUTIVADASMULHERESTUKANO}

A relação entre o atendimento médico ocidental e os conhecimentos tradicionais dos povos indígenas sobre saúde e doença é uma questão importante para a antropologia. Buchillet (1991), analisando a relação entre os sistemas tradicionais de saúde e doença dos povos indígenas e o sistema médico ocidental, relata que a maior parte dos povos indígenas no Brasil possui seus sistemas tradicionais como recurso principal em termos de atendimento à saúde e recomenda que as políticas públicas de assistência à saúde indígena sejam articuladas aos sistemas tradicionais próprios. Para a autora, a visão do processo de adoecimento e a concepção de corpo e saúde dos povos indígenas têm como referência suas representações sociais de corpo, saúde e doença. A doença inexiste fora do contexto sociocultural, e o processo de saúde e doença acontece a partir das representações socioculturais da doença dentro de cada sociedade, revelando-se nas dimensões subjetiva, biofísica e sociocultural (Buchillet, 1991).

Os recursos médicos tradicionais são parte de um sistema integrado e estruturado, e não podem ser desvinculados da sua totalidade. A antropologia da doença busca demonstrar a coerência interna e racional do pensamento tradicional, através das interpretações e comportamentos dos indivíduos frente à doença. Nesse sentido, nas sociedades tradicionais, quando o indivíduo adoece, as causas do adoecimento estão relacionadas com as representações sobre o ser humano, com as atividades que o indivíduo desempenha na sociedade e com o meio ambiente em que está localizado. A doença não pode ser compreendida sem a avaliação do contexto sociocultural e ambiental em se inscreve. É nesse sentido que os eventos que ocorrem durante o período reprodutivo das mulheres são imediatamente inscritos na totalidade de seus contextos socioculturais e ambientais, havendo sempre uma busca das causas sociocosmológicas relacionadas com infrações de regras culturais de comportamento, dietas, ou outras causas como feitiços ou questões ambientais.

No final dos anos 90, havia um grande descontentamento nas comunidades da região de Iauaretê $\hat{e}^{3}$ (ver Figura 1) quanto ao atendimento à saúde reprodutiva ${ }^{4}$ das mulheres. A percepção das mulheres, professoras indígenas ${ }^{5}$ e lideranças da Associação das Mulheres Indígenas de Iauaretê (AMIDI) indicavam que muitas mulheres morriam de parto. As mortes eram referidas pelas professoras indígenas como causadas por hemorragia ou "inchamento do corpo" anterior ao parto. O acesso aos serviços de saúde era prejudicado pela dificuldade de as mulheres se locomoverem sozinhas e pela vergonha de serem atendidas por profissionais de saúde não-índios e, em geral, homens. Além disso, havia muitos relatos de mortes maternas ocorridas nos anos imediatamente anteriores, tanto por falta de atendimento médico moderno

${ }^{3}$ Iauaretê é um pequeno centro urbano em expansão (Andrello, 2006) construído em torno de uma missão salesiana, fundada em 1929. Cada bairro desse centro urbano possui uma organização política semelhante à de uma comunidade tradicional: o capitão é a liderança responsável pelos trabalhos comunitários, pela resolução de problemas que ocorram com os moradores de seu bairro e por organizar reuniões, festas ou rituais. $O$ vicecapitão, o catequista e o animador são as outras lideranças locais. O acesso até Iauaretê é feito por rio, através de barcos ou voadeiras (pequena canoa de alumínio com motor de popa). De barco, a viagem dura cerca de cinco dias a partir de São Gabriel da Cachoeira; de voadeira, cerca de dois dias. Na época da pesquisa, esse povoado ainda não contava com comunicação por telefone, instalada em 2001. Existe um gerador que funciona com óleo diesel, e as casas possuem eletricidade durante grande parte do dia. No quartel do pelotão do exército, que fica ao lado da cidade, existe um ambulatório dirigido por um médico, que atende também aos índios. Havia, na época da pesquisa, um pequeno hospital da missão, dirigido por uma irmã salesiana, atualmente desativado; e havia também um hospital construído pelos militares na época do programa Calha Norte, todo equipado, porém nunca chegou a ser aberto (mais tarde, em 2004, foi aberto sob responsabilidade do SUS).

${ }^{4}$ A Conferência Internacional sobre População e Desenvolvimento do Cairo, em 1994, definiu saúde reprodutiva como "o bem estar geral, tanto físico, mental e social, da pessoa humana, por tudo que envolve o aparelho genital, suas funções e seu funcionamento, e não somente a ausência de doença ou de enfermidade".

${ }^{5}$ A maior parte dos professores indígenas na região do rio Negro é composta de homens, mas, em Iauaretê, já em 1997, mais ou menos, existiam muitas mulheres professoras, e foi com elas que o trabalho de campo foi iniciado. 

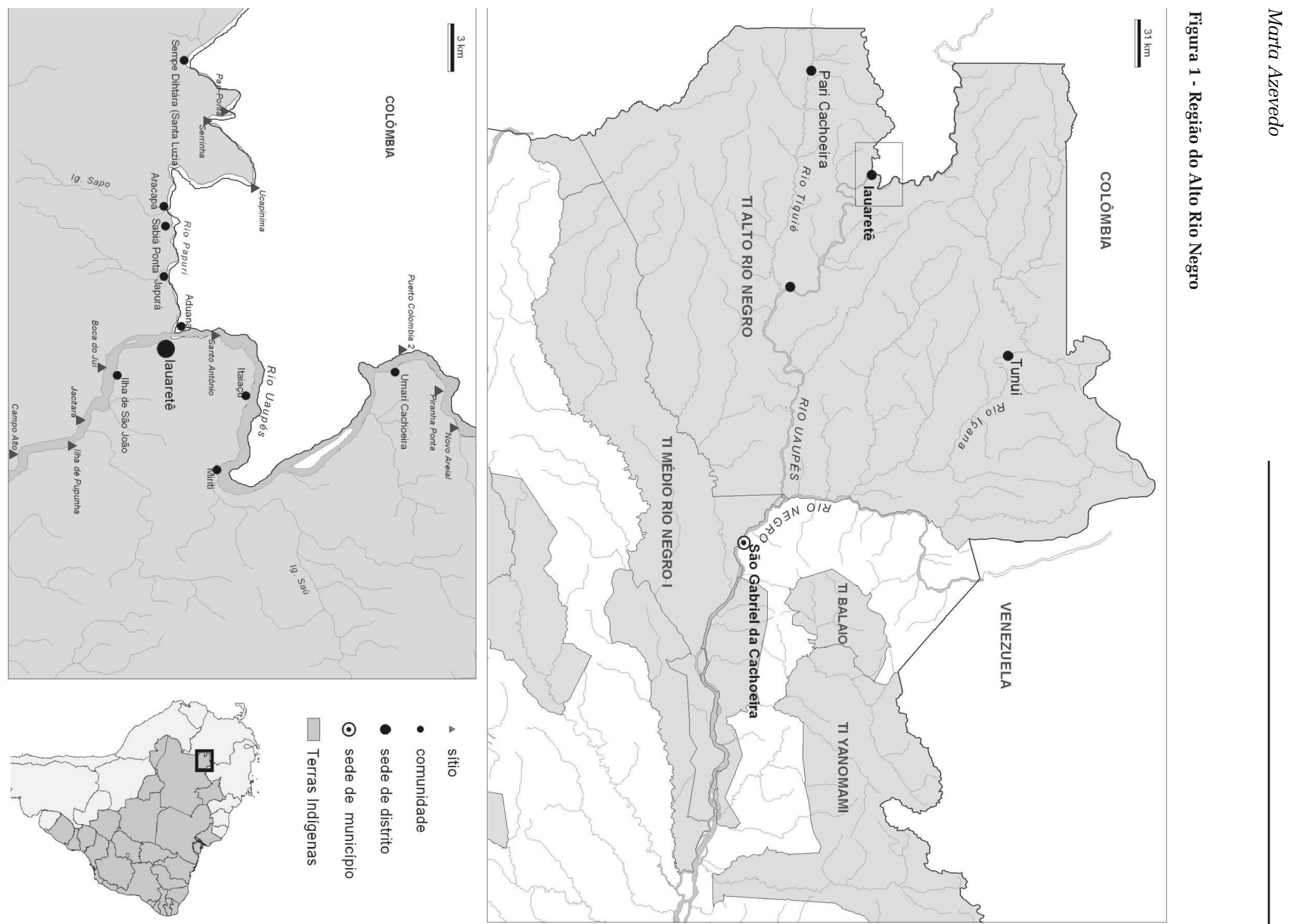
(ocidental) como por falta de cuidados tradicionais. Conforme o relato das professoras, os cuidados tradicionais estavam se perdendo e sendo desvalorizados, principalmente entre as mulheres mais jovens. As professoras referiam-se ao fenômeno como um conflito entre gerações, pois as mais jovens não acreditavam mais nos cuidados tradicionais, e as mais velhas já não se mostravam dispostas a transmitir os seus conhecimentos.

A percepção das professoras de Iauaretê foi confirmada, em grande medida, pela primeira etapa da pesquisa-ação sobre saúde reprodutiva, com a aplicação de um questionário aberto a 60 mulheres indígenas de Iauaretê e comunidades adjacentes, do rio Tiquié e de comunidades próximas da cidade de São Gabriel da Cachoeira. A principal conclusão extraída dessas informações é que, de fato, existe um sistema de conhecimentos e cuidados tradicionais com a saúde das mulheres, articulado com os demais sistemas de vida desses povos rio-negrinos. No momento da pesquisa, as mulheres mais velhas, com maior número de filhos, praticavam os cuidados tradicionais com a saúde, incluindo os métodos tradicionais de contracepção, mas as mulheres mais jovens possuíam menor conhecimento do sistema tradicional e não o praticavam com a mesma frequência. ${ }^{6}$ Outra conclusão importante foi que quanto mais próxima a comunidade indígena do hospital e do centro urbano (seja Iauaretê mesmo ou São Gabriel da Cachoeira), maior a desvalorização dos conhecimentos tradicionais próprios a essas mulheres.

O objetivo do segundo momento da pesquisa-ação foi de construir um diálogo entre as concepções tradicionais das mulheres tukano em relação ao seu ciclo de vida e a sua saúde, e os conhecimentos ocidentais sobre o tema, na perspectiva apontada por Buchillet (1991). Iauaretê foi o povoado escolhido para o desenvolvimento da pesquisa devido à sugestão de professores e pela presença da AMIDI.

A pesquisa se desenvolveu por meio de: a) conversas informais com o grupo de mulheres das

${ }^{6} \mathrm{O}$ processo de perda dos conhecimentos tradicionais ou suas transformações não foram objeto dessa investigação. diferentes etnias tukano que frequentavam a sede da AMIDI; b) entrevistas em profundidade e conversas individuais com quatro mulheres visando a coletar suas histórias de vida; c) encontros realizados com um grande número de mulheres da região, de aproximadamente três dias de duração, nos moldes de 'grupos de discussão'.

Tratando-se de conversas e encontros entre culturas e línguas completamente distintas, um instrumento acabou se revelando especialmente útil: desde o primeiro momento, quando ainda eram montados os glossários com termos de saúde reprodutiva nas línguas tukano e português, decidiu-se fazer desenhos. Os desenhos foram levados aos encontros, onde receberam acréscimos - enquanto novos desenhos eram feitos pelas participantes. Ao final dos dois encontros, havia uma série de 70 desenhos, que funcionaram como importante instrumento para debater e conhecer as concepções sobre saúde da mulher, tanto ocidentais quanto tradicionais. Os desenhos do corpo são um registro vivo da troca: resultado das próprias observações e experiências das mulheres sobre seus corpos, com os ensinamentos dos Kumu, ${ }^{7}$ das sogras e mães, e ainda dos aprendizados escolares dessas mulheres.

A conclusão extraída dessas conversas e encontros foi que os conhecimentos que as mulheres possuem sobre seu corpo e os cuidados com a saúde reprodutiva são amplos e profundamente relacionados à cosmovisão desses povos. Além disso, o debate entre os profissionais de saúde não-índios e as mulheres mostrou-se muito produtivo, pois ficou explícita a necessidade de formação dos profissionais para o atendimento específico às mulheres. Observou-se também a necessidade de planejar um trabalho de educação para saúde, voltado para essa população, realizado na língua de cada comunidade, partindo do entendimento dos sistemas tradicionais de cuidado com a saúde das mulheres. Até chegar a essas conclusões, no entanto, um longo caminho havia sido percorrido, todo ele traçado nos desenhos.

O Kumu é um benzedor, rezador; geralmente, cada comunidade ou família extensa tem um Kumu que também tem a função de acompanhar partos, cuidar de recém nascidos etc. 


\section{O corpo}

A língua majoritária falada pela população de Iauaretê é o tukano, usado como língua franca de comunicação entre eles. Cada pessoa adulta fala geralmente três línguas: sua língua original (Desana, Tuyuka, Pira-tapuya etc), o tukano e o português. Durante as conversas e entrevistas, cada mulher dava sua opinião sobre uma determinada parte do corpo, sua nomenclatura em tukano, a tradução do termo para o português e todas discorriam sobre as relações entre os órgãos reprodutivos e suas funções (Figura 2).

As mulheres da AMIDI relacionaram a denominação da vagina - que, na tradução literal para o português, seria 'porta do feto' - com o mito de sua criação. A concepção da 'abertura' da mulher está relacionada com o mito "O Cataclismo de Güramiye” (Lana, 1995). Segundo o autor, o mito relata que, quando a canoa ou cobra mítica vinha subindo o rio, carregada dos PamÖr)mahsã, ou Gente de Transformação, estes queriam criar as Malocas das Flautas Sagradas. Para isso, deram o cigarro sagrado para as filhas do trovão Buhpupõrãnome fumar, e uma delas engravidou. Quando estava pronta para dar à luz, o homem que a tinha engravidado, Boreka, viu que ela ainda não tinha vagina, somente o buraquinho para urinar; por isso, ele mediu a "porta do feto" com sua forquilha ou suporte do cigarro, e a cortou

Figura 2 - Desenho do corpo da mulher

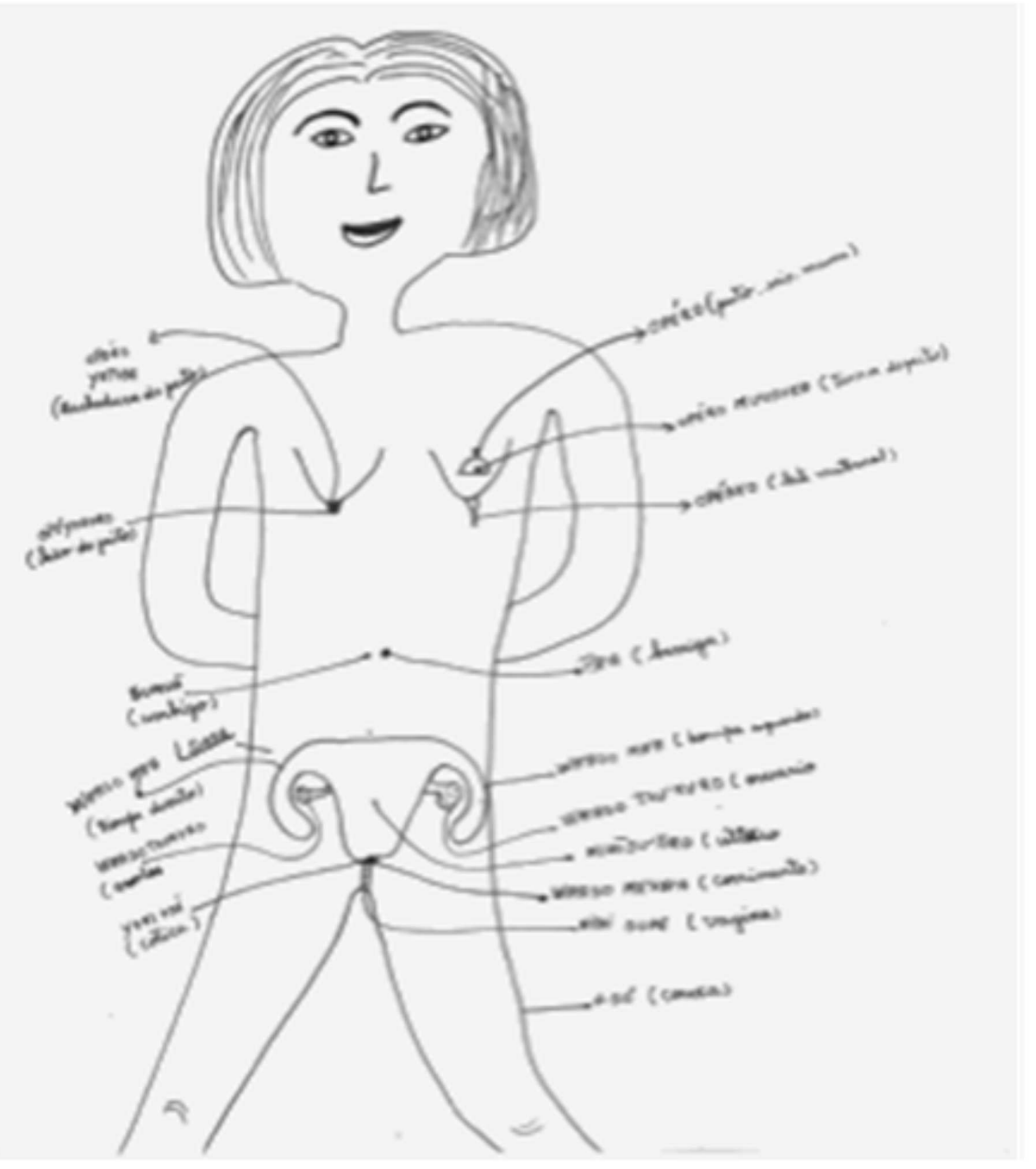


com seu brinco. A vagina ficou sendo denominada como a "porta do parto' (em tukano, nihîsupe ${ }^{8}$ ). A palavra nihî quer dizer feto, e muitas outras palavras relacionadas com os órgãos reprodutivos e gravidez são derivadas desse radical.

\section{A IMPORTÂNCIA DOS FLUÍDOS CORPORAIS}

Como Silverwood-Cope ará-maku, o criador Idn Kamni, fez os seres a partir de uma mistura de sua saliva com a terra. Diemberger (1996) mostra que, para os Khumbo do Nepal, o corpo é parte do cosmo, repleto de sinais e valores. A mulher transmite o sangue para a criança, e o homem, os ossos. Os homens transmitem os ossos, que são a parte dura do corpo humano, e, por isso, os Khumbo acreditam que a transmissão do clã deve ser feita pelo pai. Dessa transmissão dos clãs deriva a transmissão do território masculino específico, reservado aos homens. Os Khumbo possuem uma identidade que é relacionada com o território sagrado de cada subgrupo, e o corpo, portanto, estará relacionado a esse território. O parentesco khumbo é concebido através das idéias de sangue e osso, em que os ossos são os laços consanguíneos herdados do pai e passados para os filhos. O esperma define a consanguinidade, e o sangue feminino a afinidade. Um nenê khumbo é considerado como formado pelo sangue da mulher que gera seu sangue e sua carne, e o esperma que forma os ossos e um tipo de alma ligado ao ciclo do renascimento e às montanhas sagradas, para as quais todos os mortos voltam, sendo a moradia dos ancestrais.

No rio Negro, ocorre algo semelhante: as mulheres transmitem o sangue pelo cordão umbilical, e os homens os ossos (Hugh-Jones, S., 1979). As mulheres de Iauaretê relataram que o feto é formado pela junção do wahsó feminino, traduzido

${ }^{8}$ A grafia das palavras em tukano segue aquela proposta por Ramirez (1997). Apenas no caso de algumas palavras sobre as quais as mulheres discordavam da grafia proposta utilizou-se aquela sugerida por elas. Note-se que todas as mulheres participantes da pesquisa sabiam ler e escrever, a maioria delas tendo estudado até a 6 série no internato de Iauaretê. como o óvulo ou um fluído expelido pelas mulheres durante a relação sexual com o wahsó ou esperma masculino. Também no Rio Negro o sangue das mulheres e o "esperma feminino" definem a afinidade, enquanto que o esperma masculino define a consanguinidade.

O sangue e os fluídos corporais são considerados extremamente importantes pelas mulheres do Rio Negro. Através deles fluem para a geração seguinte algumas das características fundamentais dos povos. E essa importância não se limita apenas ao grupo, mas a toda a região: a mulher porta a afinidade para as comunidades vizinhas ou distantes. Desse modo de entender a importância dos fluidos deriva um comportamento fundamental: a mobilidade feminina. Ela espalha a afinidade e articula as comunidades através das alianças políticas. Assim, as alianças de sangue aqui poderiam ser entendidas diferentemente das alianças de sangue ocidentais, em geral vistas como alianças de consanguinidade.

\section{Menstruação}

O papel articulador dos fluidos se mostra com a puberdade. Na primeira menstruação, há a abertura do corpo das mulheres, que se torna apto para receber o esperma masculino. O corpo se abre para o sangue descer. Desde a primeira menstruação, as mulheres ficam "abertas", pois tanto têm mais poder quanto podem apresentar certo perigo para outras pessoas. O poder vem da presença do sangue, que representa a fertilidade e, ao mesmo tempo, o contato com o mundo pré-humano. De maneira inversa, elas também se tornam vulneráveis, e, portanto, devem proceder de determinadas formas para se proteger, não piorar ou não se contaminar. Devido a isso, elas têm de manter certo confinamento.

S. Hugh-Jones (1979), que trabalhou com o grupo tukano Barasana, dessa mesma região, estabeleceu a relação simbólica da cabaça cheia de cera de abelha, usada nos rituais, com o sangue menstrual. Os Barasana acreditam que a cera de abelha 
é identificada com o fígado, e, por sua vez, para as mulheres de Iauaretê, esse órgão seria o reservatório de sangue, o "criador" de sangue. Os Barasana dizem ainda que, quando a cera de abelha se queima, transforma-se numa substância escura e dura, que cheira a sangue menstrual. Da mesma maneira, nessa concepção de menstruação, a mulher, por estar aberta, entra em contato com o mundo préhumano, e a cabaça com breu queimando é usada também em rituais, pois se espera que ajude nessa relação com outra esfera. Assim, a menstruação, por

Figura 3 - Reclusão de moça tariana

\section{Materiais de benzimento}

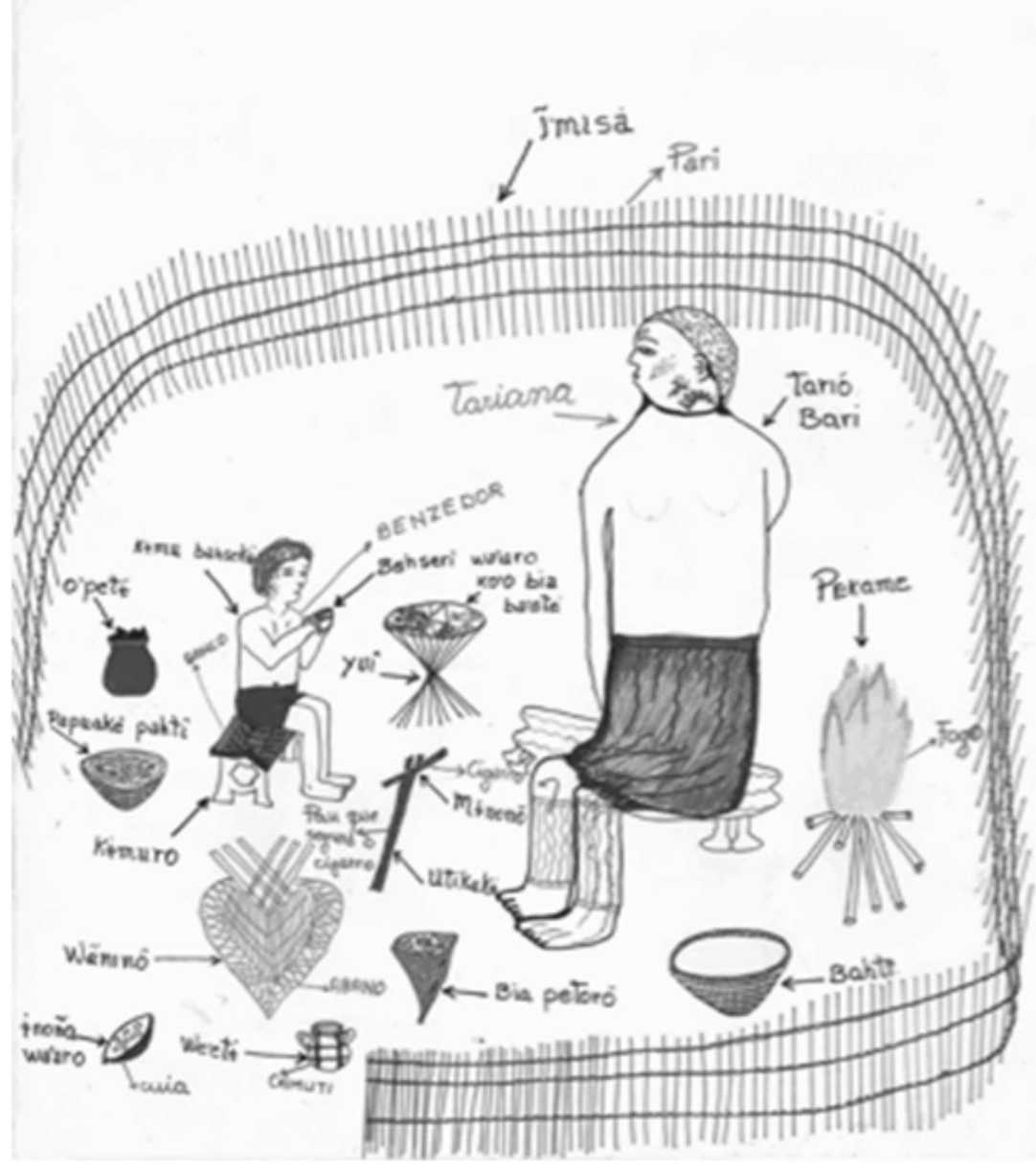

logia dos Barasana, essa periodicidade faz com que ela possa sobreviver mais do que os homens. No nível cosmológico, a menstruação está relacionada com a alternância dos períodos de seca e chuva: a menstruação das mulheres traz a alternância e renova a possibilidade de se reproduzir.

Por isso o comportamento especial nesse período de mudança: por ocasião da menarca, a moça fica confinada numa repartição dentro da casa, feita por uma espécie de biombo de tiras trançadas (Figura 3). Após esse período de confinamento, ela pode tomar banho no rio, mas deve ir acompanhada do Kumu, que a benze queimando breu na cabaça e recitando encantamentos para protegê-la do calor do dia e dos peixes pequenos do rio, que poderiam entrar em sua vagina aberta. ${ }^{9}$

Durante a primeira menstruação, o Kumu deve benzer a moça, e esse benzimento consiste em "abri-la" simbolicamente. É um momento muito importante. O trabalho deve ser feito de maneira competente, pois muitos males são oriundos de um erro. Uma transgressão alimen-

9 Todos os benzimentos são específicos de cada sib e de cada povo. Além disso, estão relacionados com mitos, que também variam de acordo com os povos e sibs da região. Não nos foi possível coletar os mitos relacionados, de cada povo ou sib. Apenas descrevemos, de maneira geral, algumas formas de benzer e a sua importância no cuidado com a saúde reprodutiva de todas as mulheres tukano. Buchillet (1990) analisa o poder das palavras nas récitas dos Kumu ou Yai (pajés de mais alta hierarquia e com mais poder do que os Kumu) e a relação metafórica ou de semelhança existente entre as palavras e os veículos através dos quais as palavras adquirem poder. 
tar ou uma atitude contrária às regras, como tomar banho no rio quando menstruada, pode ter consequências sérias. Durante todo tempo, a moça deve ficar reclusa, sem ver nem falar com outras pessoas, exceto sua mãe e o Kumu. Só deve tomar banho ao final da menstruação, e depois de ter sido benzida. As mulheres mais velhas também poderiam fazer o benzimento, colocando, simbolicamente, uma espécie de biombo feito de tiras trançadas à volta da moça, para que peixinhos pequenos não penetrem em sua vagina, e uma espécie de balaio em sua cabeça, para que seus cabelos não fiquem queimados com a urina do sol. Além dessas, muitas outras etapas e récitas são mencionadas (Figura 4). Todos os objetos de uso pessoal da moça também são bentos, assim como os alimentos que ela ingere nesse período e logo após. Além da pintura corporal que e feita nesse momento, espreme-se o sumo da pimenta no nariz, para que ela fique com a pele do rosto corada e brilhante. Se o Kumu não recitar o benzimento da primeira menstruação corretamente, a moça pode contrair doenças ou ter partos difíceis.

\section{Concepção do feto}

A concepção do feto ocorre através de inúmeras relações sexuais. $O$ feto é formado aos poucos, pela união do wahsó (sêmen) masculino com

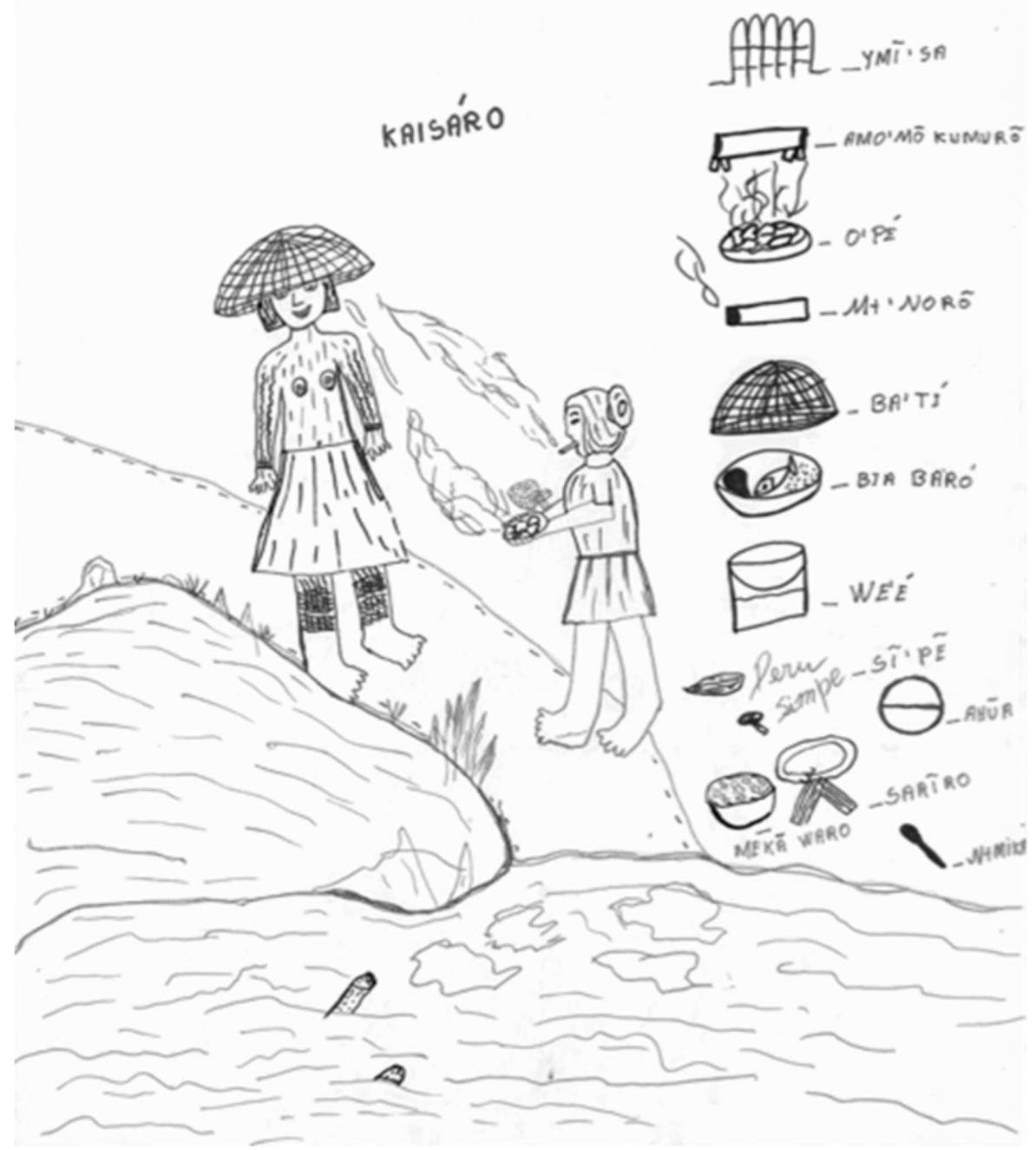


o wahsó feminino. Não nos foi possível conferir com exatidão o que é este wahsó feminino: algumas mulheres o identificaram aos óvulos ou ovários nos desenhos, outras relataram que o wahsó feminino só ocorre com a relação sexual. Seria, nesse caso, uma substância gelatinosa produzida durante o orgasmo feminino. O sêmen do homem é responsável pela formação dos ossos do feto, e o sangue da mulher, transmitido pelo cordão umbilical, forma a carne e o sangue.

A mulher grávida é chamada de nihîpahkó (mãe de feto, nihî: feto, pahkó: mãe), o marido da mulher grávida é chamado de nihîpahkï, ${ }^{10}$ ou pai de feto. Todos os nomes dos elementos relacionados ao feto possuem essa palavra na sua composição. Por exemplo: nihîkoó, água do feto; nihîsuhpê, porta do feto ou vagina; nihîsutiró, útero ou lugar de conter ou carregar o feto; nihîkumunó, banco do feto ou placenta. A placenta, ou nihîkumunó, tem um valor simbólico muito importante, pois é o banco cerimonial do feto, que se desenvolve com ele. $\mathrm{O}$ menino ou a menina, durante o ritual de iniciação, ganha um banco-kumunó - que o (a) acompanhará para o resto de sua vida. Esse banco tem relações com o mito de criação e transformação de cada povo, e é decorado com uma pintura relacionada com o sib e povo de cada pessoa. O feto, que "já vem com seu banco", possui uma identidade social, mesmo estando ainda na barriga da mãe.

\section{Gravidez, parto e dietas}

Antigamente, a mulher dava à luz na roça, que é o espaço feminino. Com suas crenças, ela não podia parir em casa, devido ao perigo do contágio pelo sangue do parto. Antes de ela voltar para casa, era necessário o Kumu queimar breu na cabaça e benzer todo o lugar, tanto para proteger esse lugar dos perigos do sangue como para proteger a mulher com a criança. Depois de voltar para casa com o filho, a mulher ficava isolada por um período de,

${ }^{10}$ Estou usando o "i” com tremas para identificar o som da vogal geralmente grafada com "u" cortado ou com "i" cortado, pronunciada como um "a”, levantando-se a língua progressivamente. em média, três dias, o que varia de acordo com a cicatrização do umbigo do recém-nascido, quando a mãe e o pai devem ficar quietos em suas casas. Posteriormente a esse período, é dado o primeiro banho do recém-nascido. O Kumu deve outra vez benzer e indicar as comidas a serem ingeridas, bem como os objetos do recém-nascido. Essa benção deve ser feita queimando-se breu e soprando a fumaça em cima dos elementos que estão sendo bentos.

Na época em que as mulheres davam à luz na roça, o parto era acompanhado de longe por um Kumu. Com a mudança para locais reservados dentro da aldeia, ele passou a ficar mais perto, mas ainda sem contato direto com a mulher. Sem ver diretamente a cena, o Kumu vai benzendo, conforme as necessidades, durante o trabalho de parto. Se um bebê está demorando muito a sair, por exemplo, o Kumu pode lançar mão de um benzimento que é feito com o caroço da uva amazônica (regionalmente denominada cucura), que é muito escorregadio, semelhante ao caroço da jabuticaba, e auxiliaria, simbolicamente, a passagem do bebê pela vagina. Ou pode lançar mão das unhas do tatu, que têm a capacidade de escavar rapidamente por terrenos muitos duros, o que facilitaria também a saída do bebê.

As posições mais comuns para o parto são a de cócoras, com as pernas flexionadas e segurando na rede, ou deitada na rede previamente cortada para que o bebê caia em cima de um pano limpo. Quando o bebê desliza para o chão, a mulher que está ajudando no parto, em geral a sogra ou a mãe da parturiente, espera até que o cordão pare de pulsar para cortá-lo. Somente depois disso é que "nasce" a placenta. A placenta pode ser usada para passar no rosto das mulheres que adquiriram manchas no período da gravidez, e é enterrada. $\mathrm{O}$ trabalho de parto dura, em média, três a quatro horas, mas as mulheres podem sentir contrações dias antes, e é a frequência das contrações que determina que elas fiquem em casa.

Foram relatados alguns problemas de parto resolvidos pelas próprias mulheres: apresentação pélvica, braço saindo primeiro, dificuldades para expelir a placenta e outros. Para cada um desses 
problemas, elas possuem procedimentos a serem executados, com ajuda de outras mulheres mais velhas e do Kumu.
Esses métodos tradicionais são ainda empregados, mas existem muitos relatos de queixa sobre o seu não-funcionamento. As mulheres jovens relatam que os métodos contraceptivos tradicionais

Figura 5 - Pós parto

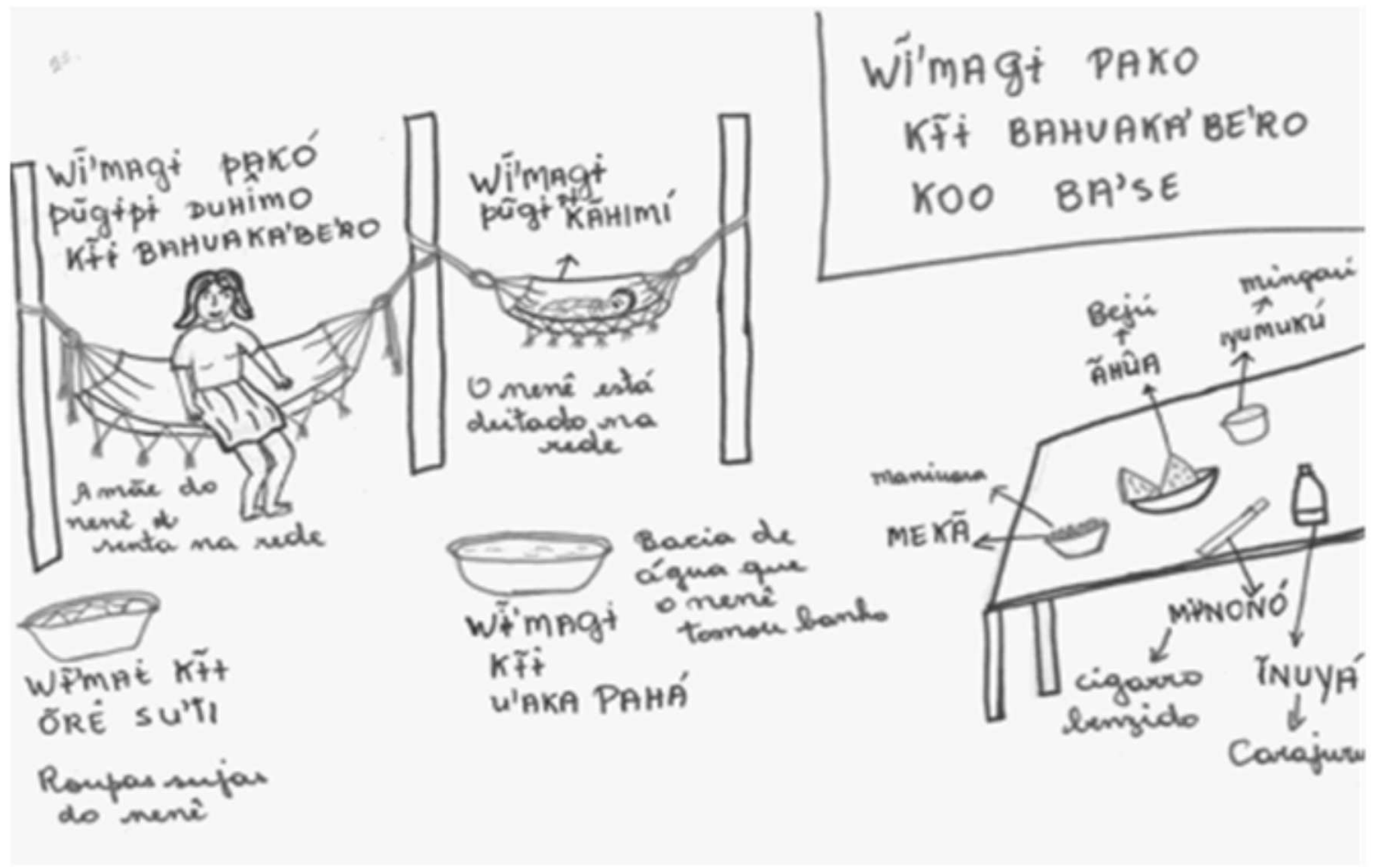

\section{Contracepção}

não funcionam mais com elas. Além disso, as moças contam que as mães ficam muito bravas quando recebem a notícia de uma gravidez indesejada, não só porque as filhas estão grávidas e não são casadas, mas porque isso quer dizer que elas tiveram inúmeras relações sexuais (para se formar, o feto necessita de muito esperma masculino), enquanto elas relatam que só tiveram uma relação sexual, na maioria dos casos. O fato de as moças terem relações esporádicas com parceiros antes do casamento pode ser aceito pelas mães, mas, em seu imaginário, a gravidez das filhas prova que elas não se limitaram ao esporádico, mas namoraram muito, e com um intervalo curto entre uma relação e outra.

A gravidez indesejada é a primeira questão mencionada pelas mulheres de Iauaretê quando se fala em saúde reprodutiva. Existem muitos casos de mulheres maduras e jovens que foram mães de crianças geradas em relações com os militares, 
e todos eles trazem conflitos com relação às crenças tradicionais. As crianças são criadas pelos avôs, pois o avô é quem transmite a elas o pertencimento étnico do seu grupo. Mas esse arranjo não é aceito pacificamente. Existem conflitos com as mães solteiras e certo mal estar com relação a essas crianças. Geralmente, quando há uma separação entre casais, os filhos tendem a ficar com seu pai, e a mulher pode voltar para sua comunidade de origem, ficando disponível para se casar outra vez. Os filhos de não-índios não só não ficam com o pai, como ficam sem identidade étnica, a não ser aquela dada pelo avô.

\section{FECUNDIDADE DAS MULHERES TUKANO, BARE, BANIWA E MAKU}

A seguir ,são apresentadas informações sobre a fecundidade das mulheres tukano, baré, baniwa e maku da região Alto Rio Negro e seus determinantes próximos, com o objetivo de avaliar os níveis e padrões de fecundidade por etnias e compreender o comportamento reprodutivo dessas mulheres face às concepções próprias sobre sua saúde. Os indicadores estimados são as taxas específicas de fecundidade por idade (TEF), taxas de fecundidade total (TFT), idade média ao nascimento do primeiro filho vivo e intervalo entre os nascimentos vivos ou intervalo intergenésico. As mulheres foram agrupadas por etnias. As mulheres Tariana foram agrupadas com as tukano, pois, apesar de serem um povo de língua aruak, estão casadas há décadas com os tukano, convivendo na mesma sub-região e possuindo concepções sobre saúde reprodutiva semelhantes. As Coripaco foram incluídas entre as Baniwa, pois são culturalmente muito próximas e residem, em sua grande maioria, na mesma sub-região do rio Içana; as mulheres werekena foram incluídas entre as Baré, pelo mesmo motivo anterior, proximidade cultural e de residência; e as mulheres pertencentes aos diferentes povos falantes de línguas maku foram analisadas de forma conjunta, identificadas sob o etnônimo Maku. As informações sobre fecundidade para esse último grupo de mulheres são poucas e de má qualidade, excluídas das análises as mulheres que não informaram a sua idade e a idade de seus filhos nascidos vivos, sobreviventes ou mortos.

Para estimar esses indicadores, foram extraídas do Censo Indígena Autônomo do Rio Negro de 1992 as seguintes informações: a) etnia, idade da mãe estimada pelo ano aproximado de nascimento; b) idade dos filhos vivos e mortos; c) data do óbito dos filhos mortos. Foram excluídos os filhos natimortos. Estão incluídas, nas estimativas, todas as mulheres solteiras, casadas, viúvas e separadas, que, em 1992, tinham entre 15 e 49 anos, o que corresponde ao período reprodutivo. As informações sobre mulheres que tiveram filhos antes dos 15 e depois dos 50 anos de idade foram excluídas.

Para evitar excessivas flutuações dos valores dos indicadores de fecundidade ${ }^{11}$ causadas pelos pequenos números, foram estimadas taxas médias para o período 1990-92 (Pagliaro; Azevedo; Santos, 2005).

As taxas de fecundidade total (TFT) das mulheres baré, baniwa, tukano e maku, no período de 1990 - 1992, indicam que o nível da fecundidade das Maku é o mais alto, sendo a TFT de 6,4 filhos nascidos vivos em média; o mais baixo nível é o das mulheres baré, 4,8 (Tabela 1). As

Tabela 1 - Taxas de fecundidade total e específicas por idade das mulheres baré, baniwa, tukano e maku, no período de 1990 - 1992

\begin{tabular}{|c|c|c|c|c|}
\hline idade & Tukano & Baniwa & Baré & Maku \\
\hline 15 a 19 & 0,06 & 0,13 & 0,03 & 0,17 \\
\hline 20 a 24 & 0,21 & 0,19 & 0,21 & 0,25 \\
\hline 25 a 29 & 0,26 & 0,20 & 0,24 & 0,26 \\
\hline 30 a 34 & 0,26 & 0,21 & 0,18 & 0,32 \\
\hline 35 a 39 & 0,21 & 0,14 & 0,16 & 0,07 \\
\hline 40 a 44 & 0,09 & 0,11 & 0,10 & 0,17 \\
\hline 45 a 49 & 0,04 & 0,03 & 0,04 & 0,03 \\
\hline TFT & 5,68 & 5,11 & 4,83 & 6,35 \\
\hline
\end{tabular}

${ }^{11}$ A fecundidade é entendida como a relacão entre nascimentos vivos e mulheres em idade reprodutiva, num determinado momento do tempo. A TFT corresponde ao número médio de filhos que uma mulher teria ao terminar o período reprodutivo, e é uma medida que não é influenciada pela distribuição etária das mulheres estudadas, sendo obtida a partir das taxas específicas de fecundidade por idade (TEF), que correspondem ao número médio de nascimentos por mulher nas diferentes faixas etárias. 
Gráfico 1- Distribuição relativa das taxas específicas de fecundidade das mulheres baré, baniwa, tukano e maku, no período de 1990 - 1992

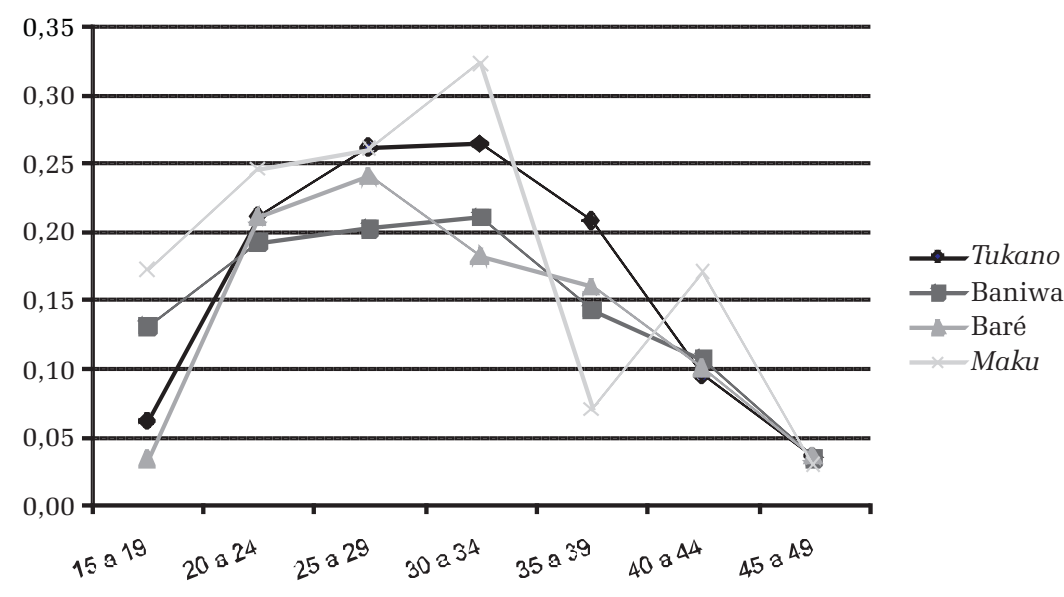

cerrado mato-grossense, encontrou uma TFT de 5,36 filhos para o período de 1979 a 1981. Os Kaiabi possuíam uma taxa de fecundidade total de 6 filhos entre $1970 \mathrm{e}$ 1979, e de 9,5 filhos entre os anos de 1990 e 1999 (Pagliaro, 2002).

Entre os Kaiabi do Xingu, (Pagliaro, 2002, 2005), o final do período reprodutivo ocorre entre 40 e 44 anos; a maior proporção de nascimentos se dá entre as idades
TFTs das Tukano e Baniwa são, respectivamente, de 5,7 e 5,1 filhos. Em relação à fecundidade por idade, o mais alto nível encontra-se na faixa etária de 30-34 anos para as mulheres tukano, maku e baniwa, e apenas as baré têm sua fecundidade máxima alcançada em faixa etária mais jovem, de 25 a 29 anos. A estrutura de fecundidade das mulheres maku é mais jovem do que a das mulheres tukano, baré e baniwa, sendo a contribuição das mulheres menores de 30 anos de idade na fecundidade total dessa etnia a mais alta.

As taxas de fecundidade total registradas por Early e Peters (1990) entre os Yanomami estão entre 8,7 e 7,5 nascidos vivos. Os autores demonstram que, em todos os períodos estudados, o padrão da fecundidade não muda, e, no início do período estudado, em 1958, as taxas específicas e totais foram mais altas, pois a estrutura etária, nesse período, era muito incomum, pois teriam ocorrido epidemias e migrações. Nancy Flowers (1994) calculou as taxas específicas e totais de fecundidade dos Xavante por períodos de anos. A taxa total de fecundidade no ultimo período calculado (1972 a 1977) foi de 9,4 filhos por mulher, tendo sido demonstrado que os níveis de fecundidade dos Xavante estavam aumentando. Somente no período do contato, 1947-51, essa taxa foi de 11,17 filhos. De 1987 a 1990, a TFT era de 8,42. Picchi (1994), no estudo sobre os Bakairi, um povo do de 25 a 29 anos para as mulheres que já tinham seu período reprodutivo completo ou quase completo, e entre as idades de 20 a 24 anos para as mulheres de gerações mais jovens, indicando um rejuvenescimento do padrão de fecundidade dessas mulheres (2002, 2005). Características semelhantes de padrão de fecundidade foram registradas por Pagliaro e Junqueira (2007) para os Kamaiurá.

Tabela 2 - Taxas de fecundidade total, idade média ao nascimento do primeiro filho e intervalo intergenésico, Tukano, Baniwa, Baré e Maku

\begin{tabular}{l|c|c|c}
\hline & $\begin{array}{c}\text { TFT } \\
\mathbf{1 9 9 0 - 1 9 9 2}\end{array}$ & $\begin{array}{c}\text { idade média } \\
\mathbf{1}^{\mathbf{0}} \text { filho }\end{array}$ & $\begin{array}{c}\text { intervalo } \\
\text { médio }\end{array}$ \\
\hline Tukano & 5,68 & 21,08 & 2,70 \\
\hline Baniwa & 5,11 & 19,36 & 2,86 \\
\hline Baré & 4,83 & 19,82 & 2,62 \\
\hline Maku & 6,35 & 20,23 & 3,02 \\
\hline
\end{tabular}

Fonte: CIARN/1992

As médias de idade quando do nascimento do primeiro filho vivo das mulheres pertencentes aos quatro grupos rio-negrinos variam de 19,4 a 21,1 anos. De acordo com essas estimativas, são as mulheres baniwa e baré que têm seus filhos mais cedo, respectivamente aos 19,4 e 19,8 anos, e as mulheres tukano e maku as que iniciam mais tarde a procriação, respectivamente 21,1 e 20,2 anos.

Early e Peters (1990) apontaram que a média da idade das mulheres yanomami, ao terem o primeiro filho, é de 16,8 anos. Os autores ponde- 
ram ainda que existe um retardamento proposital para a primeira gravidez, pois os Yanomami acreditam que o corpo da jovem que acaba de menstruar ainda não está com o desenvolvimento completo. Por isso, quando a menina engravida logo após a primeira menstruação, os pais podem ajudála a provocar aborto. Já entre os Kaiabi do Xingu, a média da idade ao ter o primeiro filho tende a declinar entre as coortes de mulheres analisadas por Pagliaro $(2002,2005)$ : desde a coorte 1 (mulheres nascidas entre 1950 e 1954) até a coorte 6 (mulheres nascidas entre 1975 e 1979), a média da idade passa de 18,7 e atinge os 16 anos para a última coorte (2002). Portanto, para esses povos, a média de idade ao ter o primeiro filho é menor do que entre os povos aqui estudados.

O intervalo intergenésico, ou período de tempo transcorrido entre os nascimentos vivos dos filhos das mulheres rio-negrinas, é inferior a 3 anos em média, sendo as mulheres maku e baniwa as que possuem o maior intervalo médio, respectivamente, 3 e 2,8 anos. O maior intervalo intergenésico encontrado entre os Yanomami é de 3,2 anos, sendo um pouco mais alto do que o encontrado entre as mulheres do rio Negro (Early; Peters, 1990). Price (1994) calculou o intervalo médio entre os nascimentos para os Nambiquara de 2,5 anos para o período de 1976 a 1986 e, para os Kaiabi, os intervalos intergenésicos variam de 2,4 a 3,1 anos (Pagliaro, 2002, 2005).

\section{CONSIDERAÇÕES FINAIS}

Neste artigo, procuramos analisar as concepções das mulheres indígenas da região do Alto Rio Negro relativas ao seu corpo e aos eventos relacionados à saúde reprodutiva. Para os tukano, a humanidade anterior à existência dos homens atuais vivia em um estado pré-humano, pois não havia afinidade, nascimentos, casamentos. Essa humanidade continuou existindo após a série de transformações e criações dos diferentes povos a partir da viagem da "canoa-cobra", e as pessoas, quando morrem, vão se unir a esses ancestrais (Hugh-Jones,
1979). Os homens podem entrar em contato com essa pré-humanidade em diferentes momentos e espaços, tendo os xamãs como mediadores, contato esse que assegura a continuidade da existência desses povos, garantindo a continuidade da ordem social estabelecida e, portanto, a saúde coletiva. As pessoas também podem entrar em contato com esse estado pré-humano quando sonham, quando estão doentes, ou quando as mulheres menstruam ou vão dar à luz, além dos períodos rituais. As mulheres estão relacionadas a esse mundo pré-humano através de seu sangue, menstrual e do parto. Elas detêm o poder da reprodução biológica através do sangue, e os homens detêm o poder da reprodução da ordem social. Dessa maneira, durante os períodos da menstruação e do parto, as mulheres estão em contato com esse estado pré-humano, assemelhando-se aos xamãs, que entram em contato com esse mundo de maneira voluntária, para realizar curas ou rituais. Durante esses períodos, as mulheres podem ser perigosas e, ao mesmo tempo, vulneráveis. O poder do sangue da mulher é equivalente e complementar ao poder dos ossos (flautas sagradas) dos homens. O feto se forma através do sangue da mulher, que dá origem ao sangue e à carne, e o esperma do homem, que dá origem aos ossos.

O controle sobre a fecundidade das mulheres tukano se dá pelos benzimentos e (ou) uso de plantas contraceptivas. Esse controle é maior nas primeiras idades do período reprodutivo, o que se confirma na análise dos indicadores de fecundidade, por exemplo, nas médias de idade quando do nascimento do primeiro filho, de 19 a 20 anos nas diferentes etnias. As mulheres jovens, antes de se casar, pedem a um Kumu que faça um benzimento para que não tenham filhos até o momento do casamento ou um pouco depois. Durante o casamento, a fecundidade é controlada mais frequentemente pelo espaçamento entre os filhos. O período de "dieta" das mulheres, quando deve haver a ausência de relações sexuais, é de dois anos, segundo o relato das mulheres de Iauaretê. Essa informação também é confirmada pelos intervalos intergenésicos encontrados, de 2,6 a 3 anos. 
O outro período em que a mulher lança mão dos benzimentos contraceptivos é no final do seu perí odo reprodutivo, quando pedem ao Kumu para benzê-las de forma que não mais engravidem, interrompendo definitivamente seu período reprodutivo. É o benzimento da menopausa, que pode ser realizado assim que a mulher sente os primeiros sintomas do climatério ou já teve inúmeros filhos.

Comparando-se os níveis da fecundidade dessas mulheres do Alto Rio Negro, com exceção das mulheres maku, com os encontrados entre outras populações indígenas, nota-se que eles são um pouco mais baixos do que aqueles encontrados para os Xavante, Kaiabi e Yanomami, exceção feita aos Bakairi.

(Recebido para publicação em julho de 2009) (Aceito em setembro de 2009)

\section{REFERÊNCIAS}

ADAMS, K.; PRICE, D. The demography of small-scale societies: cases studies from Lowland South America. South American Indian Studies, Vermont, EUA, Bennington College, n.4, 1994.

ANDRELLO, Geraldo. Cidade do índio - Transformações e cotidiano em Iauaretê. São Paulo: Editora Unesp. Instituto Socioambiental e NUTI/UFRJ. 2006.

AZEVEDO, M.M. Demografia dos povos indígenas do Alto o Rio Negro: um estudo de caso de nupcialidade e reproduㄱ. ção. 2003. Tese (Doutorado) -Unicamp. Campinas,SP, 2003.

ช่ BUCHILLET, D. Los poderes del hablar. Terapia y agresión

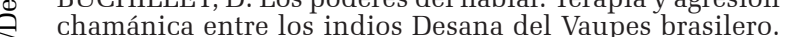
of In: BASSO, E.; SHERZER, J. (Ed.). Las culturas nativas \& latinoamericanas a traves de su discurso. Quito: Coedición ^ MLAL/Abya-Yala, 1990. (Coleción 500 años, n.24)

. A questão da integração dos sistemas médicos: problemas e perspectivas - uma introdução. In:

¿. Medicinas tradicionais e medicina ocidental. Belém, $\overline{\mathrm{PA}}$ : Ed. CEJUP. 1991.

FLOWERS, Nancy. Demographic crisis and recovery: case study of the Xavante of Pimentel Barbosa. In: ADAMS

Z K.; PRICE, D. The Demography of Small-Scale societies: cases studies from Lowland South America. South American Indian Studies, Vermont, EUA, Bennington College, n. 4, 1994.
FOIRN/ISA. Povos indígenas do Alto e Médio Rio Negro. Uma introdução à diversidade cultural e ambiental do noroeste da Amazônia brasileira. Brasília: Ministério da Educação, SEF, [1994] 2000.

HUGH-JONES, Christine. From the Milk River: statial and temporal processes in northwest amazonia. Cambridge: Cambridge University Press, 1979.

HUGH-JONES, Stephen. The Palm and the Pleiades. Initiation and cosmology in northwest Amazonia. Cambridge: Cambridge University Press, 1979.

LANA, Firmiano Arantes; LANA, Luiz Gomes. Antes o Mundo não existia. São Gabriel da Cachoeira, AM: UNIRT/ FOIRN, 1995

PAgliaro, H. A revolução demográfica dos Povos Indígenas no Brasil: a experiência dos Kaiabi do Parque Indí gena do Xingu, Mato Grosso, Brasil - 1970-1999. 2002. 197 f. Tese (Doutorado em Saúde Pública) - Programa de Pós-Graduação em Saúde Pública da Universidade de São Paulo. 2002

. A revolucão demográfica dos povos indígenas: a experiência dos Kaiabi do Parque Indígena do Xingu, Mato Grosso. In: ; AZEVEDO, M.M.; SANTOS, R.V. (Org.) Demografia dos Povos Indígenas no Brasil. Rio de Janeiro: Editora Fiocruz/Abep, 2005. p.79-102.

; JUNQUEIRA, C. Recuperação demográfica e fecundidade dos Kamaiurá, povo Tupi do Parque Indígena do Xingu, Brasil Central, 1970-2003. Saúde e Sociedade, São Paulo, v.16, n.2, p.37-47, 2007.

; AZEVEDO, M.M.; SANTOS, R.V. Demografia dos povos indígenas no Brasil: um panorama critico. In: ; $\quad$; (Org.). Demografia dos Povos Indígenás no Brasil. Rio de Janeiro: FIOCRUZ/ABEP, 2005 p.11-32.

POZZOBON, J. A. H. Parenté et demographie chez les indiens Maku. 1991. These (Doctorat), Paris: Université de Paris VII, 1991.

RAMIREZ, H. A fala tukano dos Ye'pâ-Masa - tomos I, II e III, respectivamente: Gramática, Dicionário e Método de Aprendizado. Manaus: Inspetoria Salesiana Missionária da Amazônia, 1997

RIBEIRO, Berta G. Os índios das águas pretas. São Paulo: Cia. Das Letras/EDUSP. 1995.

SILVERWOOD-COPE, Peter L. Os Makú: povo caçador do noroeste amazônico. Brasília: Ed. UnB, 1990. 


\section{REPRODUCTIVE HEALTH AND INDIGENOUS WOMEN OF THE HIGH RIO NEGRO}

\section{Marta Azevedo}

The present paper describes and analyzes High Rio Negro indigenous women's own conceptions about reproductive health, relating them to fecundity indicators. Qualitative information point to a detailed and complex knowledge that area's indigenous women possess on their bodies and the care with their health. The fecundity levels and age patterns are related with the women's ethnicity, and, therefore, to the traditional healthcare system of these peoples. This research was developed between 1997 and 2003, in the Iauaretê area Indigenous Land High Rio Negro (AM), and had as first source of data Rio Negro's Autonomous Indigenous Census. CIARN., executed by the Federation of Rio Negro's Indigenous Organizations. FOIRN. in 1992.

KEYWORDS: indigenous peoples, the northwestern Amazon, indigenous health, demography and health, women's health.

\section{SANTE POUR LA REPRODUCTION ET LES} FEMMES INDIGENES DU ALTO RIO NEGRO

\section{Marta Azevedo}

Dans cet article on décrit et on analyse les conceptions spécifiques qu'ont les femmes indigènes du Alto Rio Negro en ce qui concerne la santé de la reproduction, et on y fait le lien avec les indicateurs de fécondité. Les informations qualitatives montrent une connaissance détaillée et complexe que possèdent les femmes indigènes de cette région en ce qui concerne leur corps et les soins liés à la santé. Les niveaux et les structures d'âge de la fécondité sont mis en relation avec l'ethnie des femmes, c'est-à-dire avec les systèmes traditionnels de soins relatifs à la santé de ces peuples. La recherche a été faite de 1997 à 2003, dans la région de Iauaretê, Terre Indigène de l'Alto Rio Negro (AM), les premières données utilisées ont été celles fournies par le Recensement Indigène Autonome du Rio Negro - CIARN-, réalisé par la Fédération des Organisation Indigènes (Federação das Organizações Indígenas) du Rio Negro-FOIRN - en 1992.

MoTs-CLÉs: peuples indigènes, nord-ouest de l'Amazonie, santé indigènes, démographie et la santé, santé des femmes.

Marta Azevedo - Doutora em Demografia, área de concentração em Demografia Antropológica e Demografia de Etnias pela Universidade Estadual de Campinas. Pesquisadora do Núcleo de Estudos de População (NEPO) da UNICAMP e sócia colaboradora do Instituto Socioambiental. Antropóloga especialista em populações indígenas, especificamente povos Guarani e povos da região do Alto Rio Negro, estado do Amazonas. Trabalha com demografia e educação, indicadores sociais e demografia e saúde das mulheres, bem como questões relacionadas com a metodologia para captação de informações populacionais sobre povos indígenas. Foi coorganizadora do volume "Demografia dos Povos Indígenas no Brasil” (2005). 
